\title{
Hubungan Diabetes Mellitus Terhadap Kejadian Disabilitas untuk Activities of Daily Living (ADL) Di Indonesia
}

\author{
The Relationship Diabetes Mellitus With Disability for Activities Of Daily Living (ADL) In \\ Indonesia.
}

\author{
Halimah Siregar ${ }^{a^{*}}$, Krisnawati Bantas ${ }^{\mathrm{b}}$ \\ ${ }^{a *}$ Ikatan Ahli Kesehatan Masyarakat Indonesia, Bidang Sumber Daya Manusia, Jalan Pengangsaan Timur 16 Cikini, Indonesia \\ ${ }^{\mathrm{b}}$ Departemen Epidemiologi, Fakultas Kesehatan Masyarakat Universitas Indonesia, Lantai 1 Gedung A, Kampus UI Depok, Indonesia
}

\section{A B S T R A K}

Diabetes Mellitus salah satu PTM tertinggi didunia, prevalensi global diabetes di antara orang dewasa di atas 18 tahun telah meningkat dari 4,7\% pada 1980 menjadi $8,5 \%$ pada 2014 . Penelitian yang dilakukan Edward ditemukan bahwa> 50\% orang tua dengan diabetes melaporkan kesulitan melakukan tugas fisik sehari-hari. Hal ini sejalan dengan penelitian Rindra bahwa individu yang menderita diabetes akan berisiko 3kali (95\% CI; 2.860-3.288) dibandingkan individu yang tidak menderita diabetes untuk mengalami disabilitas. Tujuan penelitian ini melihat hubungan diabetes mellitus dengan kejadian disabilitas untuk aktivitas kehidupan sehari-hari (ADL). Penelitian ini desain cross sectional data IFLS 2015, di analisis sampai multivariat menggunakan Regressi Logistik. Adapun variable penelitian ini ialah (Diabetes Mellitus, disabilitas, usia, jenis kelamin, pendidikan, obesitas dan hipertensi). Jumlah studi partisipan semua yang memenuhi kriteria inklusi sebanyak 3408 partisipan. Variable pada penelitian ini adalah Disabilitas, Diabetes Mellitus, Obesitas, Hipertensi, Jenis Kelamin, Usia dan Pendidikan. Definisi operasional pada variable dependen ialah disabilitas jika salah satu dari 6 item ADL membutuhkan bantuan dan atau tidak mampu melakukannya. Diabetes Mellitus pada penelitian ini individu yang pernah di diagnose tenaga kesehatan dan sedang minum obat DM. Tidak ada hubungan antara diabetes mellitus dengan kejadian disabilitas dengan secara statistika dengan nilai POR 1.225 (95\%CI ; 0.379-3.958). Pada variable kovariat hanya usia dengan rentang (75-90 $\left.0^{\text {th }}\right)$ yang berhubungan secara statistika terhadap kejadian disabilitas untuk aktivitas kehidupan sehari-hari (ADL) dengan nilai POR 2.172 (95\% CI;1.117-4.222). Tidak ditemukan hubungan diabetes mellitus dengan kejadian aktivitas kehidupan seharihari (ADL) dengan nilai POR 1.225 (95\%CI ; 0.379-3.958) dibandingkan dengan individu yang tidak menderita diabetes mellitus.

Kata kunci: Diabetes Mellitus, Disabilitas, ADL, IFLS 2015

\section{Pendahuluan}

Penyakit Tidak menular (PTM) penyumbang terbesar kematian pertama di dunia sebesar 73\%, lalu diikuti Penyakit menular dan Kecelakaan (Injuries) pada tahun 2017. Salah satu PTM penyumbang terbesar di dunia ialah Diabetes Mellitus. ${ }^{1}$ Menurut WHO Jumlah penderita diabetes telah meningkat dari 108 juta pada 1980 menjadi 422 juta pada 2014. Prevalensi global diabetes di antara orang dewasa di atas 18 tahun telah

\section{A B S T R A C T}

Diabetes Mellitus is one of the highest Noncommunicable Disease (NCD) in the world, global prevalence of diabetes among adults more than 18 years has increased from $4.7 \%$ in 1980 to $8.5 \%$ in 2014. Research conducted by Edward found that more than $50 \%$ of parents with diabetes reported difficulty for activities of daily. In line with Rindra's research that people who has diabetes will have three times to get risk (95\% CI; 2,860-3,288) than people who has not diabetes to get incidence of disability. The aim of these study to forward the relationship between diabetes mellitus and the incidence for disability activities of daily life (ADL). This study a cross-sectional design used of the 2015 IFLS data, analyzed till multivariate with Logistic Regression. This research variable is (Diabetes mellitus, disability (ADL), age, gender, education, obesity and hypertension). The number all of study participants who met the inclusion criteria was 3408 participants. The operational definition of the dependent (ADL) variable is disability, if one of the $6 \mathrm{ADL}$ items needed help and or not. Diabetes Mellitus in this study was an individual who had been diagnosed by health worker and is taking DM medication.There was no relationship between diabetes mellitus for the incidence of disability for activities of daily living with statistics value POR of 1,225 (95\% CI; 0.379-3,958). The covariate variable, only age range (75-90 years) was statistically related to get of disability activities of daily living (ADL) with value POR of 2.172 (95\% CI; 1.117-4.222) There was no association between diabetes mellitus and the incidence of daily life activities (ADL) with a POR value of 1,225 (95\% CI; 0.3793,958 ) compared with people who hasn't diabetes mellitus.

Key words: Diabetes Mellitus, Disability, ADL, IFLS 2015

meningkat dari $4,7 \%$ pada 1980 menjadi $8,5 \%$ pada 2014. Sejalan dengan Federasi Diabetes Internasional memperkirakan bahwa 425 juta orang menderita DM pada tahun 2017 dan jumlah ini diperkirakan akan meningkat menjadi 629 juta pada tahun 2045. ${ }^{2} \mathrm{Di}$ Amerika ada 61 juta orang dengan keadaan disabilitas, 2 dari 5 individu berusia 65 tahun dan lebih mengalami

*Korespondensi: Halimah Siregar, Ikatan Ahli Kesehatan Masyarakat Indonesia, bidang sumber daya manusia, jalan pengangsaan timur 16 Cikini. Email: halimahsrg26@gmail.com 
disabilitas. $26 \%$ orang dewasa tersebut memiiki beberapa jenis disabilitas. Lalu ada $16.3 \%$ orang yang menderita DM mengalami disabilitas. ${ }^{3}$ Lalu ada $16.3 \%$ orang yang menderita DM mengalami disabilitas. ${ }^{3} \mathrm{Di}$ Indonesia diabetes mellitus penyakit dengan peringkat ke2 penyumbang Disability-Adjusted life years (DALYs), dimana DALYs dihitung dengan jumlah perkiraan tahun yang hilang (YLL) dan tahun hidup dengan disabilitas (YLD) karena Diabetes Mellitus. Menurut hasil penelitian Riskesdas ada 35.53\% lansia diabetes mellitus yang mengalami disablitas ringan hingga tergantung total ${ }^{3}$

Prevalensi diabetes mellitus meningkat tajam seiring bertambahnya usia, dan diproyeksikan bahwa pada tahun 2025, sebagian besar penderita diabetes akan berusia 65 tahun atau lebih. Walaupun diabetes sering disertai oleh komorbiditas vaskular dan neuropatik. Ancaman disabilitas, hilangnya kemandirian, dan penurunan kualitas hidup pada akhirnya dapat menjadi perhatian terbesar bagi banyak individu dengan penyakit ini. ${ }^{4}$ Pada penelitian Edward ditemukan bahwa $>50 \%$ dari orang tua dengan diabetes melaporkan kesulitan melakukan tugas fisik sehari-hari. ${ }^{5}$ Sejalan dengan penelitian Rindra bahwa individu yang menderita diabetes akan berisiko 3 kali (95\% CI; 2.860-3.288) untuk mengalami disabilitas dibandingkan individu yang tidak menderita diabetes. ${ }^{6}$

Berdasarkan laporan riskesdas Prevalensi DM meningkat dari tahun 2013-2018, hal yang sama juga terjadi pada peningkatan kasus disabilitas sebesar $14.76 \%$ mulai dari ringan hingga ketergantungan total. Hal tersebut membuat peneliti ingin mengetahui apakah ada hubungan diabetes mellitus dengan kejadian disabilitas pada aktivitas kehidupan sehari-hari (ADL) di Indonesia. ${ }^{7}$

\section{Metode}

Penelitian ini menggunakan data Indonesian Family Life Survey-5 tahun 2014/2015. Pengumpulan data dilakukan pada 13 Provinsi di Indonesia yaitu 4 provinsi di Sumatra (Sumatera Utara, Sumatera Barat, Sumatera Selatan, dan Lampung), 5 provinsi di Pulau Jawa (DKI Jakarta, Jawa Barat, Jawa Tengah, DI Yogyakarta, dan Jawa Timur), dan 4 provinsi mencakup kelompok pulau besar yang tersisa (Bali, Nusa Tenggara Barat, Kalimantan Selatan, dan Sulawesi Selatan). ${ }^{8}$ Penelitian ini menggunakan desain cross sectional dan akan di analisis sampai Multivariat menggunakan uji Regressi logistik yang akan mengeluarkan nilai OR atau setara dengan nilai POR dengan confidence interval (CI) sebesar 95\% dari tiap variabel $^{9}$
Aplikasi statistika yang digunakan pada penelitian ini ialah STATA. Adapun variable penelitian ini adalah Disabilitas, Diabetes Mellitus, Obesitas, Hipertensi, Jenis Kelamin, Usia dan Pendidikan. Ada 6 item disabilitas dasar pada ADL (Activity Daily Living) yang ditanyakan dalam kuesionare IFLS 2015, yaitu ; makan, berpakaian, dandan, berjalan, mandi,dan toileting dengan melakukan observasi kuesionare buku 3B, pertanyaan pada kolom KK03f sampai KK03kc. Adapun definisi disabilitas jika salah satu dari 6 item ADL membutuhkan bantuan dan atau tidak mampu melakukannya. ${ }^{10}$ Diabetes Mellitus pada penelitian ini individu yang pernah di diagnosa tenaga kesehatan dan sedang minum obat DM. ${ }^{9}$ Cara pengukuran variable DM dengan observasi kuesionare buku 3B seksi CD (kondisi Kronis) pertanyaan CD05 dengan pertanyaan "Apakah Dokter/Paramedis/ Perawat/ Bidan pernah mengatakan bahwa Ibu/Bapak/Sdr memiliki keadaan/penyakit Diabetes Mellitus?" dan buku US seksi US (pengukuran kesehatan) pada pertanyaan US18ac "Apakah Ibu/Bapak/Sdr meminum obat untuk penyembuhan Diabetes?" Pada penelitian populasi sumber ialah kepala rumah tangga yang menjadi responden penelitian IFLS 2015. Studi partisipannya ialah responden berusia dimulai dari usia 45 hingga lansia tua 90 tahun yang memenuhi kriteria inklusi yaitu tidak menderita penyakit stroke, rematik dan berbagai jenis kanker serta memiliki data yang lengkap. Jumlah sampel pada penelitian ini sebanyak 3408 yang memiliki data lengkap sesuai kriteria inklusi.

\section{Hasil}

Tabel 1. Analisis Deskriptif Variabel Penelitian Hubungan Diabetes Mellitus terhadap kejadian Activities Of Daily Living (ADL) Di Indonesia

\begin{tabular}{lcc}
\hline Variabel & $\begin{array}{c}\text { Jumlah } \\
\mathbf{n = 3 4 0 8}\end{array}$ & $\begin{array}{c}\text { Persen } \\
\text { (\%) }\end{array}$ \\
\hline $\begin{array}{c}\text { Disabilitas } \\
\text { Ya }\end{array}$ & 3344 & 98.12 \\
Tidak & 64 & 1.88 \\
\hline DM & & \\
Ya & 132 & 3.87 \\
Tidak & 3276 & 96.13 \\
\hline Obesitas & & \\
Ya & 933 & 27.38 \\
Tidak & 2475 & 72.62 \\
\hline Usia & & \\
$\quad$ Pra lansia (45-59th) & 1998 & 58.63 \\
Lansia (60-74th) & 1097 & 32.19 \\
Lansia Tua (75-90th) & 313 & 9.18 \\
\hline Jenis Kelamin & & \\
Perempuan & 455 & 13.35 \\
Laki -Laki & 2953 & 86.65 \\
\hline Pendidikan & & \\
Tinggi & 1957 & 57.42 \\
Rendah & 1451 & 42.58 \\
\hline Hipertensi & & \\
Ya & 577 & 83.07 \\
Tidak & 2831 & \\
\hline
\end{tabular}


Tabel 2. Analisis Bivariat Hubungan Diabetes Mellitus terhadap kejadian Activities Of Daily Living (ADL) di Indonesia

\begin{tabular}{|c|c|c|c|c|c|c|c|}
\hline \multirow[t]{3}{*}{ Variabel } & \multicolumn{4}{|c|}{ Disabilitas } & \multirow[t]{3}{*}{ Nilai-p } & \multirow[t]{3}{*}{ POR } & \multirow[t]{3}{*}{ CI 95\% } \\
\hline & \multicolumn{2}{|c|}{ Ya } & \multicolumn{2}{|c|}{ Tidak } & & & \\
\hline & $\mathbf{n}$ & $\%$ & $\mathbf{n}$ & $\%$ & & & \\
\hline \multicolumn{8}{|l|}{ DM } \\
\hline $\mathrm{Ya}$ & 3 & 4.69 & 129 & 3.86 & 0.734 & 1.225 & $0.379-0.958$ \\
\hline Tidak & 61 & 95.31 & 3215 & 96.14 & & & \\
\hline \multicolumn{8}{|l|}{ Jenis Kelamin } \\
\hline Laki-laki & 59 & 92.19 & 2894 & 86.54 & 0.195 & 1.834 & $0.732-4.596$ \\
\hline Perempuan & 5 & 7.81 & 450 & 13.46 & & & \\
\hline \multicolumn{8}{|l|}{ Usia } \\
\hline Pra Lansia $\left(45-59^{\text {th }}\right)$ & 36 & 56.25 & 1962 & 58.67 & & & \\
\hline Lansia $\left(60-74^{\text {th }}\right)$ & 16 & 25 & 1081 & 32.33 & 0.47 & 0.806 & $0.445-1.460$ \\
\hline Lansia Tua $\left(75-90^{\text {th }}\right)$ & 12 & 18.75 & 301 & 9 & $* 0.02$ & 2.172 & $1.117-4.222$ \\
\hline \multicolumn{8}{|l|}{ Obesitas } \\
\hline $\mathrm{Ya}$ & 22 & 65.63 & 911 & 27.24 & 0.207 & 1.398 & $0.830-2.356$ \\
\hline Tidak & 42 & 34.38 & 2433 & 72.76 & & & \\
\hline \multicolumn{8}{|l|}{ Pendidikan } \\
\hline Rendah & 29 & 45.31 & 1422 & 42.52 & 0.655 & 0.892 & $0.543-1.467$ \\
\hline Tinggi & 35 & 54.69 & 1922 & 57.48 & & & \\
\hline \multicolumn{8}{|l|}{ Hipertensi } \\
\hline $\mathrm{Ya}$ & 7 & 10.94 & 570 & 17.05 & 0.202 & 0.597 & $0.271-1.317$ \\
\hline Tidak & 57 & 89.06 & 2774 & 82.95 & & & \\
\hline
\end{tabular}

*Signifikan $p$ value $<0.05$

Berdasarkan tabel.1 diketahui bahwa individu yang mengalami disabilitas sebesar $1.88 \%$. Individu yang menderita Diabetes Mellitus sebesar 3.87\%. Mayoritas individu berada pada kelompok usia (4559tahun). Ditemukan 27.38\% individu mengalami obesitas serta $16.93 \%$ menderita hipertensi. Individu dengan Pendidikan tinggi sebanyak 57.42\%, dan 86\% berjenis kelamin laki-laki.

Tabel 3. Model Awal Hubungan Diabetes Mellitus terhadap kejadian Activities Of Daily Living (ADL) di Indonesia

\begin{tabular}{lcccc}
\hline \multicolumn{1}{c}{ Variabel } & POR & SE & P-Value & 95\% CI \\
\hline DM & 1.341 & 0.805 & 0.624 & $0.413-0.350$ \\
JK & 2.043 & 0.965 & 0.130 & $0.809-5.157$ \\
Usia & 1.355 & 0.244 & 0.092 & $0.951-1.929$ \\
Obesitas & 1.538 & 0.415 & 0.110 & $0.906-2.611$ \\
Hipertensi & 0.539 & 0.220 & 0.131 & $0.242-1.202$ \\
\hline
\end{tabular}

Tabel 4. Penilaian Uji Konfonding Hubungan Diabetes Mellitus terhadap kejadian Activities Of Daily Living

(ADL) di Indonesia

\begin{tabular}{lcccl}
\hline Model & POR & 95\% CI & $\begin{array}{c}\text { Delta } \\
\text { POR(\%) }\end{array}$ & Keterangan \\
\hline Model Awal & 1.341 & $0.413-0.350$ & & \\
Tanpa HT & 1.311 & 0.4044 .245 & 2.28 & Bukan konfonding \\
Tanpa JK & 1.269 & $0.392-4.105$ & 5.67 & Bukan konfonding \\
Tanpa obesitas & 1.316 & $0.406-4.264$ & 1.89 & Bukan konfonding \\
Tanpa Usia & 1.310 & $0.404-4.243$ & 2.36 & Bukan konfonding \\
\hline
\end{tabular}

Tabel 5. Model Akhir Hubungan Diabetes Mellitus terhadap kejadian Activities Of Daily Living (ADL) Di Indonesia

\begin{tabular}{lccccc}
\hline Variabel & $\boldsymbol{\beta}$ & SE & P-value & aPOR & 95\%CI \\
\hline DM & 0.294 & 0.598 & 0.624 & 1.341 & $0.413-4.350$ \\
\hline
\end{tabular}

Berdasarkan Analisis pada tabel 2 disimpulkan bahwa tidak ada hubungan bermakna secara statistik pada diabetes mellitus dengan kejadian disabilitas untuk ADL dengan nilai POR 1.225 (95\%CI ; 0.379-3.958). Analisis Multivariat dilakukan setelah melewati uji seleksi kandidat hasil dari analisis bivariat dengan nilai $p$-value $<0.25$ yang masuk kedalam permodelan seperti pada tabel 3.

Pada tabel 5 terlihat model akhir dimana tidak ada hubungan antara diabetes mellitus dengan kejadian disabilitas dasar pada aktivitas sehari-hari (ADL) dengan nilai POR 1.341 (95\% CI; 0.413- 4.350). Pada penelitian ini tidak terdapat interaksi maupun konfonding seperti yang sudah di tampilkan pada tabel 4.

\section{Pembahasan}

Pada penelitian ini didapatkan bahwa diabetes mellitus tidak ada hubungan dengan kejadian disabilitas didapatkan nilai POR 1.341 (95\% CI; 0.413- 4.350). Hal Ini tidak sejalan dengan teori bahwa ada hubungan positif antara diabetes dan kecacatan dimana dapat dijelaskan bahwa diabetes menyebabkan komplikasi seperti neuropati. Neuropati ini menyebabkan perubahan motorik dan sensorik, serta cedera mikrovaskular. Yang pada gilirannya, menyebabkan pengurangan aliran darah dan kekuatan otot dan mengurangi kemampuan seseorang untuk menjalani aktivitas sehari-hari. ${ }^{11}$ 
Penelitian ini juga tidak sejalan dengan penelitian Maryam bahwa diabetes dikaitkan dengan peningkatan $67 \%$ risiko kecacatan. ${ }^{12}$ Faktor risiko diabetes dan komorbiditas menjelaskan lebih banyak hubungan antara diabetes dan kecacatan di antara orang Asia Selatan daripada orang Afrika. Hal yang sama ditemukan pada penelitian Rita bahwa orang dewasa yang lebih tua di AS dengan diabetes cenderung mengalami kesulitan dengan OR OR 2.5kali (setelah di adjusted dengan sosiodemografi) di masing-masing dari lima kelompok fungsi fisik dibandingkan dengan orang dewasa yang tidak menderita diabetes. ${ }^{13}$ Penelitian Stefanos di country wise (China, Finland, Ghana, India, Mexico, Polandia, Rusia, Afrika Selatan dan Spanyol) ditemukan hubungan antara DM dan kecacatan yang dinilai dengan pengukuran WHODAS II yang diperkirakan menggunakan regresi linier multivariat ditunjukkan setelah di kontrol dengan sosio-demografi dan merokok, diabetes dikaitkan dengan signifikan 2,46 (95\% CI 1,49-3,43) dinegara (China) hingga 6,56 (95\% CI 2,67-10,45) (Ghana) kecuali negara meksiko hanya sebesar 1.5 kali. $^{14}$

\section{Kesimpulan}

Tidak ditemukan hubungan diabetes mellitus dengan kejadian disabilitas untuk ADL dengan nilai POR 1.341 (95\% CI; 0.413- 4.350). Pada variabel kovariat ditemukan bahwa Individu dengan rentang usia 75-90 tahun berisiko 2 kali untuk mengalami disabilitas untuk ADL dibandingkan dengan individu yang berusia 45-59tahun.

\section{Ucapan Terima Kasih}

Penulis mengucapkan terima kasih kepada National Institute on Aging (NIA), National Institute for Health and Development (NICHD), dan hibah dari Bank Dunia, Indonesia dan GRM International, Australia dari DFAT, Departemen Luar Negeri dan Perdagangan. Pemerintah Australia yang telah melakukan survey IFLS 2015 dan dapat menggunakan datanya untuk dilakukan analisis oleh penulis. Penulis mengucapkan terima kasih kepada dosen pembimbing saya Dr. dr. Krisnawati Bantas, M.Kes yang telah memberikan dukungan kepada saya untuk menyelesaikan penelititan ini.

\section{Daftar Pustaka}

1.IHME. (2020, Januari Senin). https://vizhub.healthdata.org/ gbd-compare/. Retrieved from https:// vizhub.healthdata.org: https://vizhub.healthdata.org/gbdcompare/
2.WHO. 2020. Diabetes. Retrieve Juli Jumat, 2020. From http:/ /www.who.int/news-room/fact-sheet/details/diabetes

3.CDC. (2019, September Senin). Disability Impacts All of Us. Retrieved from www.cdc.gov: https://www.cdc.gov/ncbddd/ disabilityandhealth/infographic-disability-impacts-all.html

4.Balitbangkes. (2018). Laporan Nasional Riskesdas 2018. Jakarta: Badan Penelitian dan Pengembangan kesehatan, Kementerian Kesehatan.

5.Edward W. Gregg, Carol M. Mangione, Jane A. Cauley, Theodore J. Thompson, Ann V. Schwart, Kristine E. Ensrud, Michael C. Nevitt. 2002." Diabetes and Incidence of Functional Disability in Older Women"Diabetes Care Jan, 25 (1) 61-67; DOI: 10.2337/diacare.25.1.61

6.Rindra Eriska Hidayat. 2016." Analisis disabilitas terkait factor-faktor risikonya pada penduduk Indonesia usia Produktif (Berdasarkan Riskesdas 2013)" Tesis, Fakultas Kesehatan Masyarakat Universitas Indonesia. Depok.

7.Balitbangkes. (2013). Laporan Riskesdas 2013. Jakarta: Badan Penelitian dan Pengembangan kesehatan, Kementerian Kesehatan

8.Strauss, J., Witoelar, F. \& Sikoki, B. (2016) The Fifth Wave of the Indonesia Family Life Survey: Overview and Field Report. RAND Corporation, Santa Monica

9.Kleinbaum, D.G (2005) Statistic dor Biology and Health. Second. USA. Departemen of Epidemiology Rollins School of Public Health at Emory University.

10.Carolina, Mirela.(2006)." How does having diabetes affect ADL disability in elders?". Access in https:// iussp2009.princeton.edu/papers/93106

11.Mehmet Evren Okur, Ioannis D. Karantas, Panoraia I. Siafaka. Diabetes Mellitus: A Review on Pathophysiology, Current Status of Oral Medications and Future Perspectives. Acta Pharmaceutica Sciencia 55(1):61-82 • April 2017.

12.Maryam Tabesh. Et.al. (2018). Association between type 2 diabetes mellitus and disability: What is the contribution of diabetes risk factors and diabetes complications. journal of diabetes.

13. Rita Rastogi Kalyani, etal (2010)."Association of Diabetes, Comorbidities, and A1C With Functional Disability in Older Adults" Diabetes Care Vol;33 No.5.

14.Stefanos Tyrovolas, et al.(2015)."Diabetes mellitus and its association with central obesity and disability among older adults: A global perspective"Experimental Gerontology, Vol 64, April 2015, Pages 70-77

15.Hanafi.2019." Efek Gabungan Obesitas Dan Merokok Dengan Hipertensi Derajat 1 Pada Laki-Laki Dewasa (Analisis Data Indonesian Family Life Survey-5 Tahun 2014)". Tesis, Fakultas Kesehatan Masyarakat Universitas Indonesia, Depok.

16.Holt, RIG, Cockram, C, Flyvbjerg, A, \& Goldstein, BJ (eds) 2017, Textbook of Diabetes, John Wiley \& Sons, Incorporated, Hoboken. Available from: ProQuest Ebook Central. [2 July 2020].

17.Kerner, W., Brückel, J., \& German Diabetes Association (2014). Definition, classification and diagnosis of diabetes mellitus. Experimental and clinical endocrinology \& diabetes : official journal, German Society of Endocrinology [and] German Diabetes Association, 122(7), 384-386. 